\title{
The FLOod Probability Interpolation Tool (FLOPIT): A Simple Tool to Improve Spatial Flood Probability Quantification and Communication
}

\author{
Mahkameh Zarekarizi ${ }^{1,2, *(0)}$, K. Joel Roop-Eckart ${ }^{3}$, Sanjib Sharma ${ }^{1}$ and Klaus Keller ${ }^{1,3}$ \\ 1 Earth and Environmental Systems Institute, Pennsylvania State University, University Park, PA 16802, USA; \\ sanjibsharma@psu.edu (S.S.); kzk10@psu.edu (K.K.) \\ 2 Jupiter Intelligence, San Mateo, CA 94401, USA \\ 3 Department of Geosciences, Pennsylvania State University, University Park, PA 16802, USA; \\ joelroopeckartpsu@gmail.com \\ * Correspondence: mahkameh.zare@gmail.com
}

Citation: Zarekarizi, M.;

Roop-Eckart, K.J.; Sharma, S.; Keller,

K. The FLOod Probability

Interpolation Tool (FLOPIT): A

Simple Tool to Improve Spatial Flood

Probability Quantification and

Communication. Water 2021, 13, 666

https://doi.org/10.3390/w13050666

Academic Editor: Yurui Fan

Received: 20 December 2020

Accepted: 24 February 2021

Published: 1 March 2021

Publisher's Note: MDPI stays neutral with regard to jurisdictional claims in published maps and institutional affiliations.

Copyright: (c) 2021 by the authors. Licensee MDPI, Basel, Switzerland. This article is an open access article distributed under the terms and conditions of the Creative Commons Attribution (CC BY) license (https:// creativecommons.org/licenses/by/ $4.0 /)$.

\begin{abstract}
Understanding flood probabilities is essential to making sound decisions about flood-risk management. Many people rely on flood probability maps to inform decisions about purchasing flood insurance, buying or selling real-estate, flood-proofing a house, or managing floodplain development. Current flood probability maps typically use flood zones (for example the 1 in 100 or 1 in 500 -year flood zones) to communicate flooding probabilities. However, this choice of communication format can miss important details and lead to biased risk assessments. Here we develop, test, and demonstrate the FLOod Probability Interpolation Tool (FLOPIT). FLOPIT interpolates flood probabilities between water surface elevation to produce continuous flood-probability maps. FLOPIT uses water surface elevation inundation maps for at least two return periods and creates Annual Exceedance Probability (AEP) as well as inundation maps for new return levels. Potential advantages of FLOPIT include being open-source, relatively easy to implement, capable of creating inundation maps from agencies other than FEMA, and applicable to locations where FEMA published flood inundation maps but not flood probability. Using publicly available data from the Federal Emergency Management Agency (FEMA) flood risk databases as well as state and national datasets, we produce continuous flood-probability maps at three example locations in the United States: Houston (TX), Muncy (PA), and Selinsgrove (PA). We find that the discrete flood zones generally communicate substantially lower flood probabilities than the continuous estimates.
\end{abstract}

Keywords: FLOod Probability Interpolation Tool; Federal Emergency and Management Agency; continuous flood hazard map; flood hazard communication; open-source flood hazard mapping tool; probabilistic flood map

\section{Introduction}

Flooding drives sizable risks around the globe [1,2]. Between 1980-2013, global economic flood losses exceeded $\$ 1$ trillion and resulted in approximately 220,0000 fatalities [3]. Future flood risks are projected to increase driven by a complex interplay between changes in exposures, vulnerabilities, and hazards [3-6]. Knowledge of flood risks can be a key driver in community participation in flood risk mitigation planning [7].

How one communicates flood probabilities can impact decision-making [8,9]. Flood probability maps are important sources of information about floods. The information communicated through these maps impacts decisions on where to build and whether to elevate structures to prevent flood damage and purchase flood insurance $[9,10]$. Flood maps typically consist of flood zones that bin continuous and spatially varying hazards into discrete flood zones [11-15]. The outer edge of a zone is the maximum extent of a flood with a designated probability (i. e. the 1 in 100-year flood), while the inner edge 
of a zone is the maximum extent of a smaller magnitude, higher probability flood. The choice to communicate via flood zones can introduce a low-bias in flood probabilities [11]. For example, the Federal Emergency Management Agency (FEMA) in the United States, publishes 1 in 100-year (1\% annual chance) and 1 in 500 years $(0.2 \%$ annual chance) flood zones [16]. The maximum extent of the $1 \%$ annual chance flood designates the boundary between the $1 \%$ and $0.2 \%$ flood zones. Thus, the $1 \%$ annual chance flood zone is essentially the $>1 \%$ annual chance flood zone, while the $0.2 \%$ annual chance flood zone is essentially the $(1 \%, 0.2 \%)$ annual chance flood zone. Additionally, the " $x$ " zones, also termed "area of minimal flood risk", have a $<0.2 \%$ annual chance. This approach obscures the nature of continuous flooding probabilities with "in-out" flood zones [11]. The "in-out" approach can have serious consequences for flood hazard communication. [12] states that the 1 in 100-year flood zone "rapidly transformed in the community mind to a definition of flood free and flood-prone, with areas above the designated flood perceived to be flood-free-a misconception often reinforced by flood maps that shade only those portions that are subject to the designated flood". Adopting a flood zone approach neglects to communicate key information [17] and can communicate biased hazards [11] (Figure 1).

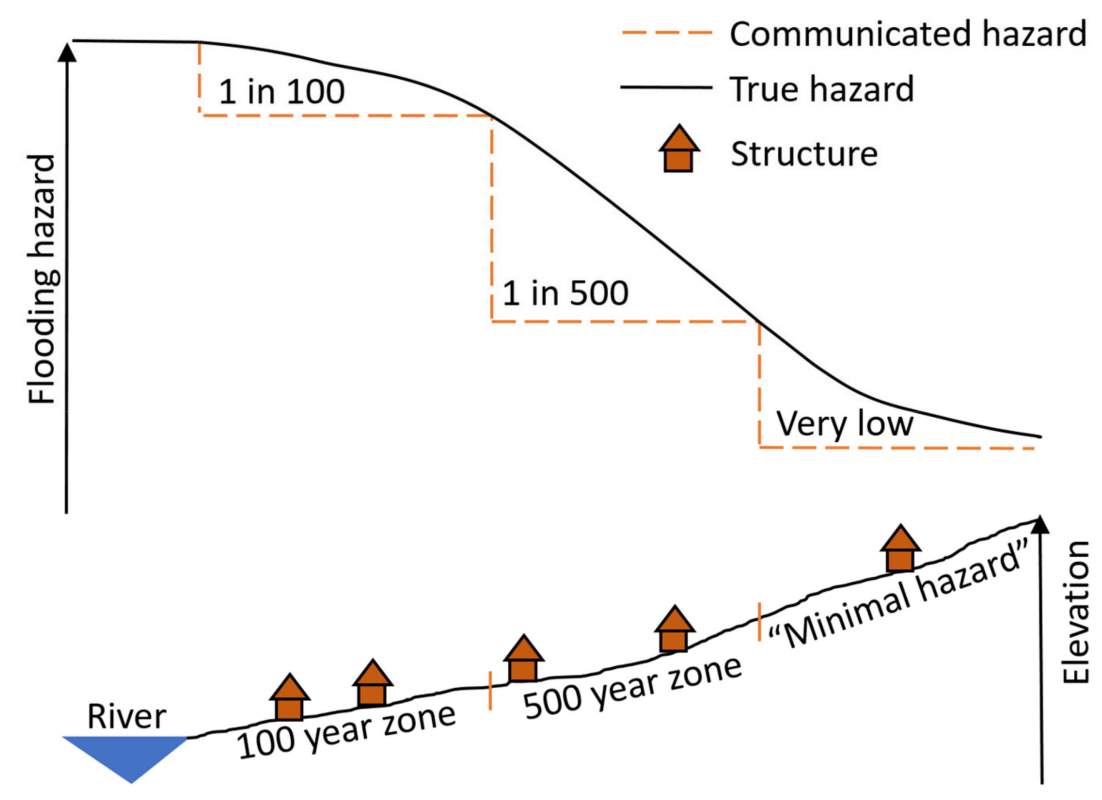

Figure 1. Schematic diagram of flood hazard communication via flood zone maps compared to the true hazard. The upper left y-axis represents the flood hazard. This is highest near the river and decreases as the elevation rises. The lower right y-axis represents elevation, in this simple illustration increasing with increasing distance from the river. Due to the way flood zones "bin" flood hazard into discrete zones, the communicated flood hazard is almost always lower than the true flood hazard.

The downward bias in the communicated flood probability and the binning associated with flood zones are well understood and communicated by flood mapping organizations [16]. However, downward biased and binned flood probabilities can present a communication barrier and the qualifiers communicated by flood mapping organizations may be ignored [18]. This barrier can be particularly problematic if people ignore risks when they view the probability as falling below some threshold level of concern, as some research suggests $[19,20]$. One approach to reducing the downwards bias is to disaggregate flood zones into smaller zones. For example, [4] produces flood maps of the contiguous United States for 10 different probability floods, while FEMA generates maps between three and six different probability floods, but publishes only the 1 in 100 and 1 in 500-year flood maps. Increasing the number of probability zones decreases the downward bias and "in-out" issues associated with "binning" probabilities, but does not solve the underlying problem. 
FEMA publishes flood risk information through Flood Risk Database (FRD; [10,16,21]). FRD is available for a limited number of riverine and coastal communities over the U.S. FRD provides water surface elevation, depth, and probabilities for extreme floods. Percent annual chance (or Annual Exceedance Probability; AEP) of flooding included in FRD is a prominent approach to communicate continuous flood risk and to avoid the in-out format of the Flood Insurance Rate Map (FIRM). FEMA estimates AEP using a log-linear interpolation between flood probability and flood surface elevation. While AEP data from FEMA's FRD address the biased communicated risk, it is only available to a limited number of communities in the U.S. and only using a log-linear interpolation method.

Here we introduce, design, implement, and demonstrate the FLOod Probability Interpolation Tool (FLOPIT). FLOPIT is a simple tool to interpolate flood probabilities between flood zone boundaries to create continuous flood probability maps. FLOPIT can be used to estimate AEP maps and return level maps for the user's choice of the return period, for any flood-prone community for which raster information for at least two return periods are available. In addition, FLOPIT provides flexibility with respect to the interpolation method.

We design FLOPIT with the goal of helping to improve (i) the communication of flood probabilities and (ii) research on decision-making under uncertainty. We demonstrate the feasibility and importance of flood probability interpolation by applying FLOPIT in three case study locations in the United States: (i) a neighborhood on the Sims Bayou in Houston, Texas, (ii) the borough of Selinsgrove, Pennsylvania, and (iii) the borough of Muncy, Pennsylvania.

\section{Materials and Methods}

FLOPIT generates continuous flood probability maps from flood water surface elevation data associated with at least two return periods plus the digital elevation model (DEM) of the area of interest. Typically, FEMA provides flood surface elevation data for 10, 100, and 500-year flood events in the United States. Additionally, DEMs are widely available in varying accuracies across the United States and the world [14,22].

FLOPIT's main inputs are the DEM raster, at least two rasters indicating the water surface elevation or depth of flooding, return periods associated with the provided flood rasters, and the interpolation method. It then relates flood surface elevations associated with provided return periods for each raster cell to corresponding exceedance probabilities using the user's choice of monotonically increasing cubic spline interpolation [23], logcubic spline, linear, or log-linear interpolation [16]. Lastly, FLOPIT interpolates the flood probability for each cell from ground surface elevations derived from a DEM (Figure 2). The user can choose to generate flood maps for new return periods not provided in the input. For this task, the return period is required as an input. FLOPIT generates water surface elevation, FIRM-like in-out flood maps, and AEP maps. Additionally, the user can choose to generate plots and more information on a specific location by providing the coordinates of the location as an input. In cases where the interpolated probability of a cell is outside the range of flood probability inputs, FLOPIT coerces a flood probability to the "zone" probability (the lowest possible probability bounded by the input data) if the cell is inside the flood extent. Cells that are outside the spatial extent of the flood maps are beyond the limit of extrapolation and coerced to a "not a number" (NA) value. 


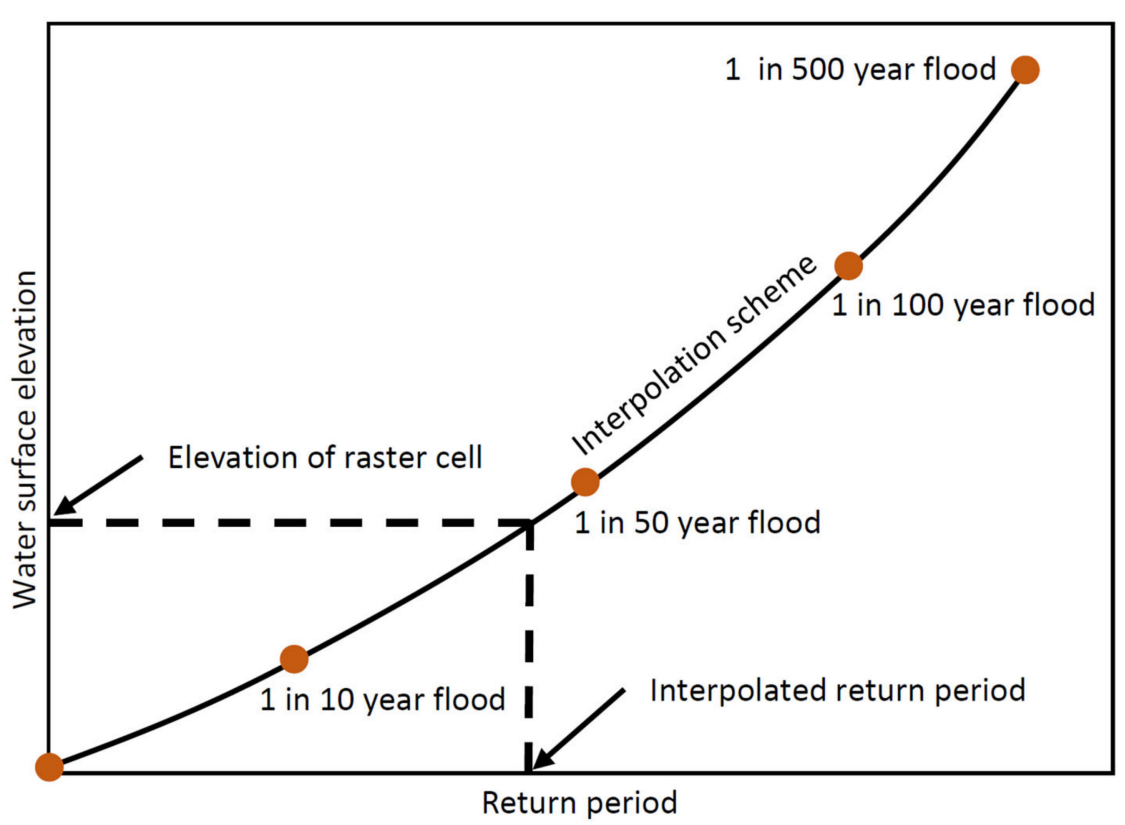

Figure 2. Conceptual diagram illustrating the FLOPIT flood surface elevation-probability interpolation approach. Flood surface elevation-probability data are not available for all flood probabilities. FLOPIT interpolates a water surface elevation to return period relationship between existing flood surface elevation-probability data. The continuous relationship is then used to interpolate flood probabilities for elevations between two flood surface elevations, producing a continuous flood probability map.

FLOPIT assigns a flood probability to all grid cells and outputs a raster file containing the flood probability map of the study area. The output flood probability map resolution is limited by the resolutions of flood surface elevation data and the DEM.

We run FLOPIT on three case studies. DEMs are retrieved from the National Elevation Dataset [24] and the Pennsylvania Spatial Data Access [25]. We use flood surface elevations with known probabilities from the FEMA flood Map Service Center databases for each location.

We assess FLOPIT's performance by comparing its outputs with FEMA FRD data. We first compare the FLOPIT-interpolated AEP map of Sims Bayou with FEMA's percent annual chance data. Furthermore, we check water surface elevation maps generated by FLOPIT using cross-validation. In the following, we discuss and explain each assessment.

We use Bias as a performance measure to validate FLOPIT. Bias measures the difference between the predicted and the benchmark variable. For example, Bias in the estimated AEP in cell $(i, j)$ is calculated as the following in Equation (1):

$$
\operatorname{Bias}(i, j)=\operatorname{AEP}^{\mathrm{FEMA}}(\mathrm{i}, \mathrm{j})-\operatorname{AEP}^{\mathrm{FLOPIT}}(\mathrm{i}, \mathrm{j})
$$

To assess the interpolated water surface elevation data from FLOPIT, we use crossvalidation. To this end, we leave one return period out and run FLOPIT for all other return periods available and estimate the left-out return levels. We then compare the estimated return level map with the map provided by FEMA as a benchmark.

\section{Results}

We first analyze the AEP maps generated by FLOPIT. The Sims Bayou is one of a few areas where we could find published FEMA flood probability maps. As FEMA uses log-linear interpolation [16], we set the interpolation method to log-linear. Results show that FLOPIT's AEP map well replicates FEMA's percent annual chance map (Figure 3). We quantify the performance in AEP estimation using Bias. The minimum, average, and maximum Bias in the study area are $-0.088,-0.001$, and 0.087 . Figure $3 \mathrm{~A}, \mathrm{~B}$ shows the 
map of AEPs from FEMA and FLOPIT over the study area. Figure 3C is the map of bias and Figure 3D shows the histogram of bias values across the area. A comparison of FLOPIT's AEP with FEMA's in-out flood zones for Muncy is depicted in Figure 4. The same comparison for the other two study regions is available in Figures S1 and S2. AEP results show that at each zone the probability of flooding is higher than or equal to the probability communicated by FEMA in-out FIRM maps (Figures S3-S5).
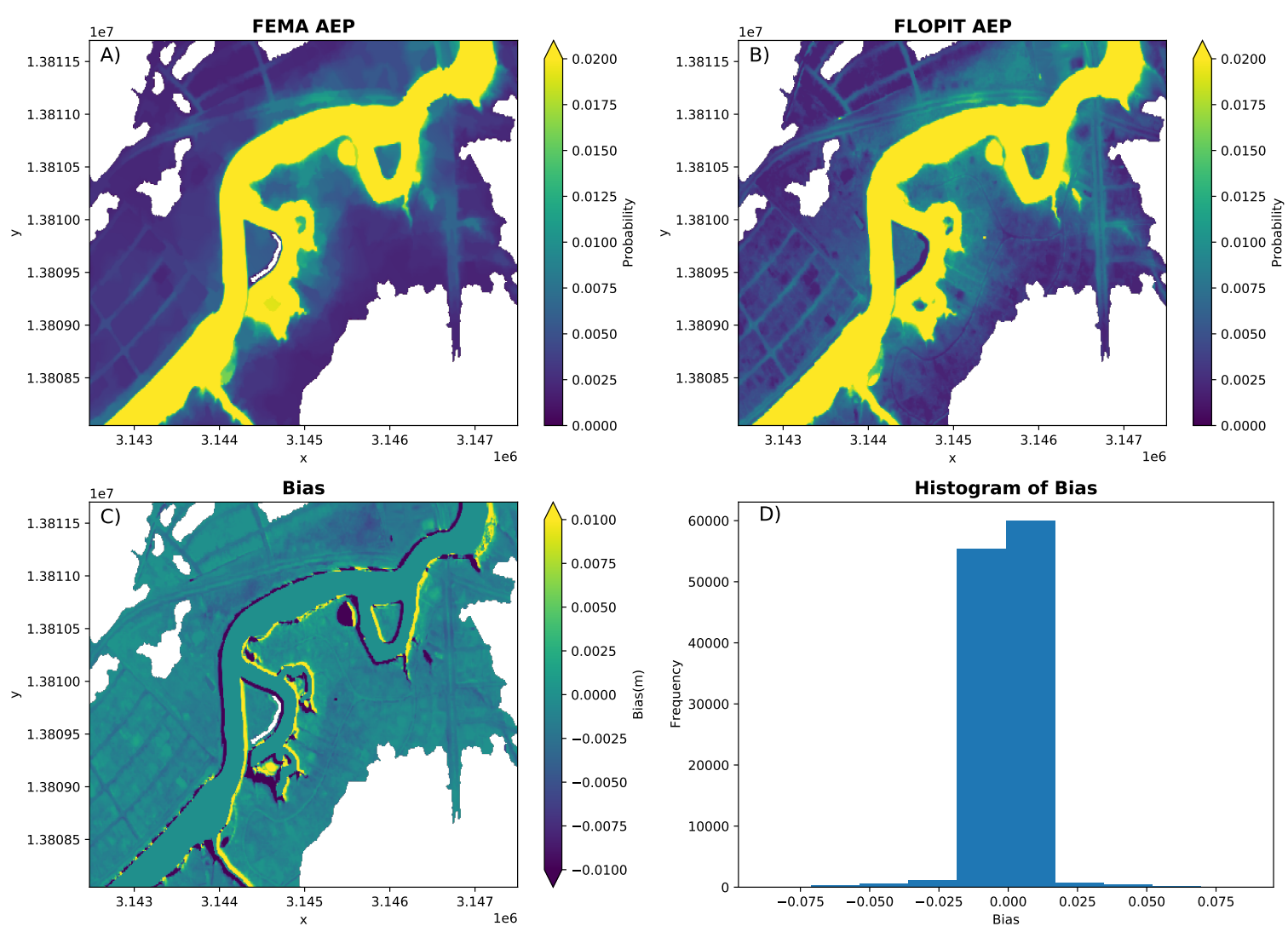

Figure 3. Comparison of the Annual Exceedance Probability (AEP) map provided by FEMA (A) as part of the Flood Risk Database with the AEP map generated by FLOPIT (B). The lower panels show the spatial distribution of bias (C) and the histogram of biases over all cells (D). FLOPIT's interpolation method is log-linear. The map is for roughly $1.5 \mathrm{~km}$ reach of the Sims Bayou in Houston (TX). Longitude bounds are [-95.302, -95.281] and latitude bounds are [29.672, 29.675].

We implement cross-validation to Sims Bayou and leave the 100-year flood out. We follow FEMA guidelines and use the log-linear method for interpolation. Figure 5 compares the FLOPIT-estimated 100-year water surface elevation map with FEMA's flood map. The minimum, average, and maximum bias in FLOPIT's estimated 100-year flood are 0.094, 0.256 , and $0.331 \mathrm{~m}$. The histogram of biases is depicted in Figure 4.

For the analyses above, we used a log-linear interpolation to replicate FEMA. However, FLOPIT allows other interpolation methods such as linear, cubic spline, and log-cubic spline. The uncertainty in the interpolation method impacts the estimated water surface elevation. We test this on the 50-year flood maps over Sims Bayou. We use cross-validation and leave the 50-year return period out using all available interpolation methods. We then compare these 50-year water surface elevation maps against FEMA's 50-year flood map that is generated based on a hydraulic dynamical model. We measure the performance of each flood map using average bias. Bias results for all interpolation methods are shown in Table 1. Results show that the log-cubic spline has the lowest average bias and is the best interpolation method for this case study. These results suggest that the log-linear method adopted by FEMA can be improved on, but has a relatively low bias. 


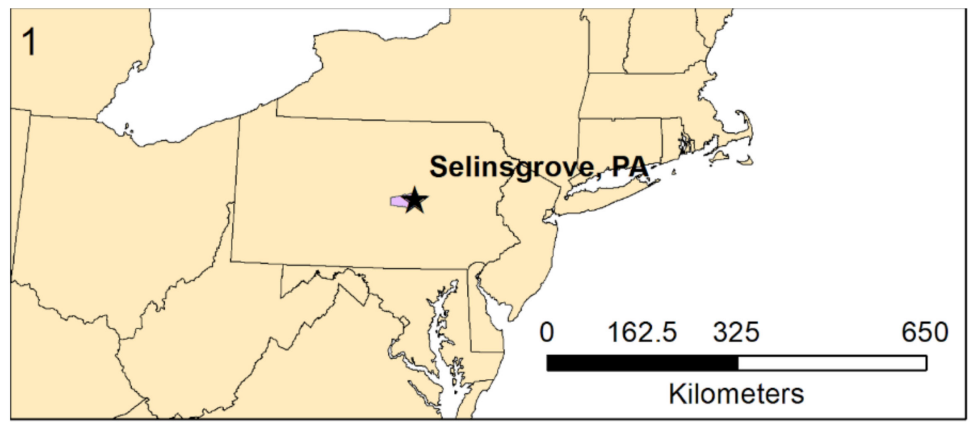

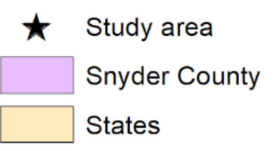

Service Layer Credits: Source: Esri,

DigitalGlobe, GeoEye, Earthstar

Geographics, CNES/Airbus DS USDA, USGS, AeroGRID, IGN, and the GIS User Community

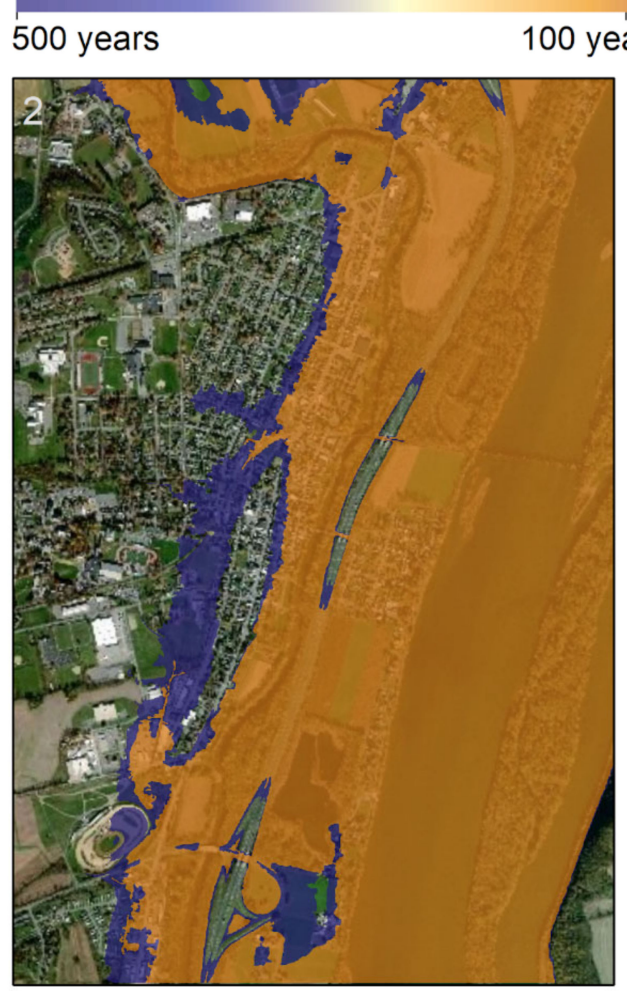

FEMA flood zones $500 y_{100}^{e^{a^{r s}}} y^{e^{a^{r s}}}$

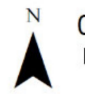

0 Kilometers

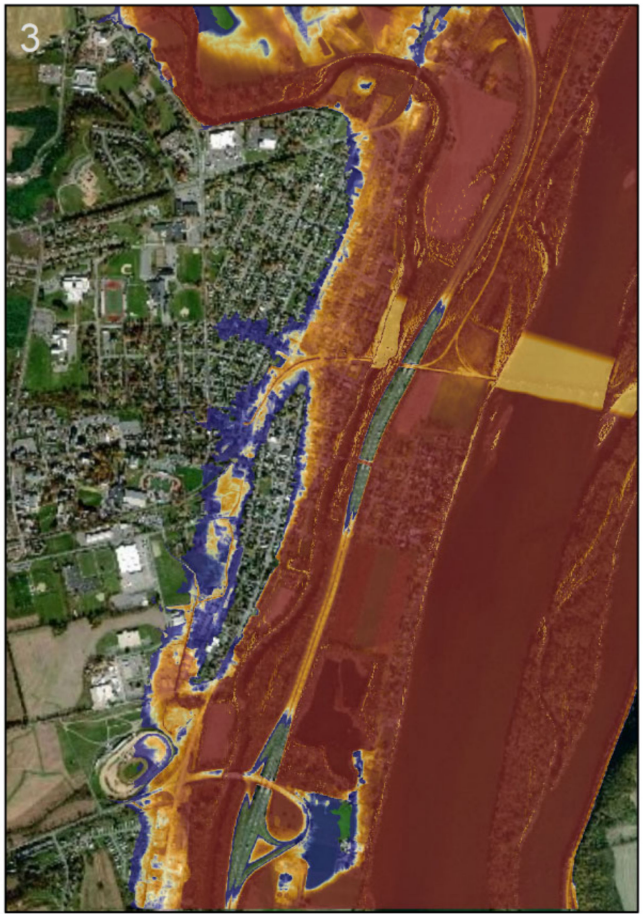

FLOPIT Interpolation

500 years

10 years

Figure 4. Map of a roughly $3 \mathrm{~km}$ reach of the Susquehanna River and tributaries at Selinsgrove, PA. Panel 1 shows the location of Snyder County and Selinsgrove, PA. Panel 2 shows the FEMA floodplains, derived from FEMA flood surface elevation data for the $1 \%$ and $0.2 \%$ annual chance (1 in 100-year and 1 in 500-year) floods. Panel 3 shows the FLOPIT interpolated flood probabilities, from $10 \%$ to $0.2 \%$ annual chance (1 in 10 -year to 1 in 500 -year). Flood probabilities are almost always higher than the flood zone communicated probabilities. The Borough of Selinsgrove stretches from the north and west edges of the map to the river and just above the Selinsgrove Speedway, with large northern and eastern sections inside the flood zones. 

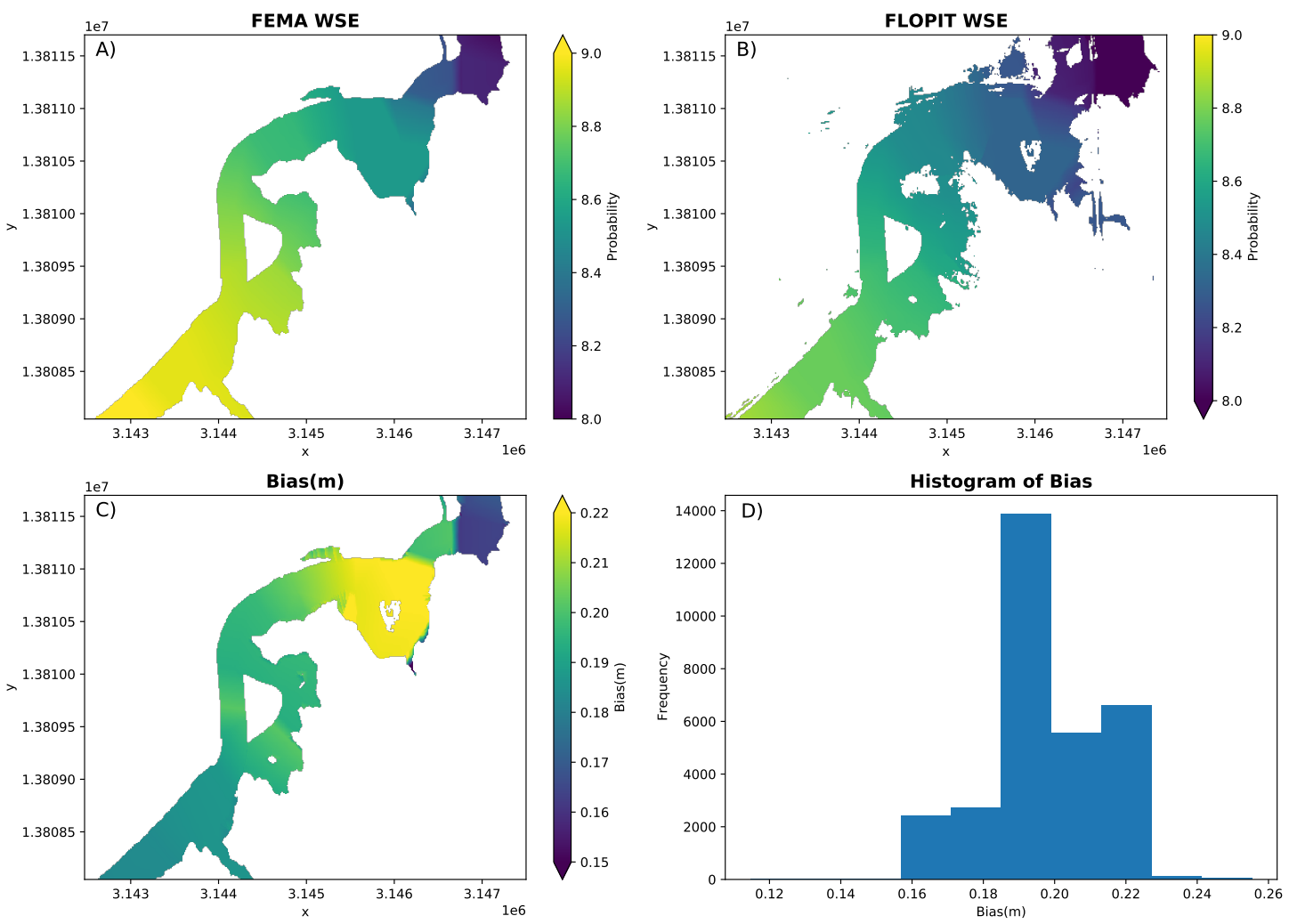

Figure 5. Comparison of the 100-year map provided by FEMA (A) as part of the Flood Risk Database with the 100-year water surface elevation map generated by FLOPIT (B). The lower panels show the spatial distribution of bias (C) and the histogram of biases over all cells (D). FLOPIT's interpolation method is log-linear. The map is for roughly $1.5 \mathrm{~km}$ reach of the Sims Bayou in Houston (TX). Longitude bounds are [-95.302, -95.281] and latitude bounds are [29.672, 29.675].

Table 1. Average bias in estimating the water surface elevation for all interpolation algorithms. The number indicated in bold has the lowest overall bias. Units are in meters.

\begin{tabular}{cccc}
\hline Log-Linear & Log-Spline & Linear & Spline \\
\hline 0.766 & 0.729 & 1.414 & 1.313 \\
\hline
\end{tabular}

We also use FLOPIT to interpolate flood probability maps for two more riverine floodprone communities, the boroughs of Muncy and Selinsgrove in Pennsylvania (Figure 4 and Figure S1). These small communities on the Susquehanna river face recurrent river flooding, but currently do not have FEMA-published flood probability maps, to the best of our knowledge. We compare FEMA's in-out flood maps with FLOPIT's probabilistic flood maps in Figure 4. There is a notable divergence between the information communicated from the two maps. The communicated flood hazard through FEMA maps is based on the zone. For example, if a property is in the 100-year zone, a user may assume that the flood chance is 0.01 or $1 \%$. However, the continuous map generated by FLOPIT shows that the flood chance is higher than $1 \%$. This could impact the cost-benefit analysis needed for any flood risk mitigation measure. For example, if a homeowner needs to estimate the Expected Annual Damages (EAD) from FEMA maps, the adopted EAD may be based on the $1 \%$ per year flood probability while FLOPIT may suggest a considerably higher value. This means that using only FEMA flood maps to estimate damages can lead to lower damage estimates and consequently a biased sense of security [9].

FLOPIT can handle flood maps at a wide range of resolutions and spatial extents. It can handle resolutions in the order of meters to kilometers, depending on the user's system computational power. The computation time scales with increasing resolution. We report approximate run times for all case studies in Table 2. The reported run times are based on 
a virtual Amazon Web Services (AWS) instance with 24 physical cores and 185 GB memory. Performance can vary considerably with the degree of aggregation and the number of cells.

Table 2. FLOPIT run times for three case studies as a function of the interpolation method. The reported numbers are wall times on a virtual Amazon Web Services (AWS) instance with 24 cores and 185 GB memory. Units are in seconds.

\begin{tabular}{ccccc}
\hline Study Area & & Sims Bayou & Muncy & Selinsgrove \\
\hline Resolution (Total Area) & & $10 \mathrm{~m}\left(18 \mathrm{~km}^{2}\right)$ & $16 \mathrm{~m}\left(400 \mathrm{~km}^{2}\right)$ & $6 \mathrm{~m}\left(100 \mathrm{~km}^{2}\right)$ \\
\hline & Log-Linear & 12.55 & 119.75 & 233.13 \\
Interpolation Method & Spline & 21.61 & 117.40 & 311.67 \\
& Log-Spline & 25.04 & 140.97 & 364.26 \\
& Linear & 10.07 & 97.92 & 179.83 \\
\hline
\end{tabular}

\section{Discussion}

We introduce FLOPIT, a flood probability interpolation tool that uses flood surface elevation-probability relationships and a digital elevation model to interpolate flood probabilities and produce flood probability (or annual exceedance probability) maps as well as water surface elevation maps for any new return period between input return periods.

Flood probability interpolation tools, such as FLOPIT, can create spatially resolved flood probability maps to help improve stakeholder communication and decision-making. FLOPIT provides spatially continuous flood hazard maps that compare favorably with flood zone maps while improving flood probability quantification. Continuous flood probability mapping also has the potential to improve flood hazard communication, stakeholder decision-making, and the setting of actuarial flood insurance rates.

FLOPIT's flexible resolution framework enables users to navigate the speed versus resolution trade-off with relative ease. Decreasing the map resolution allows for faster flood probability mapping (see Table 1 for approximate wall times). This reduces the computational demands, at the cost of a degraded spatial resolution. One could conceive scenarios where flood probability data are needed at the home scale for individual flood risk assessments or the block scale for city-wide flood risk assessments. The current version of FLOPIT is slightly parallelized using Python's Dask libraries. Future versions of FLOPIT will incorporate more extensive high-performance computing approaches for better scalability [26,27].

The current implementation of FLOPIT does not consider uncertainties in the outputs. Uncertainties in the output flood maps can stem, for example, from the measurement and resolution uncertainty in the DEM, the input flood maps as a result of nonstationarities and climate change, and the method of interpolation. The number of flood maps used as input can introduce uncertainties in the output AEP or flood maps. As the number of input flood maps increases and provided return periods better represent the overall range, this uncertainty becomes less important. However, when there are a limited number of flood maps available for input, the uncertainty in the interpolation method becomes more important. Expanding the treatment of uncertainties is an important avenue to refine FLOPIT.

Current flood hazard communication approaches typically rely on flood zones, assigning a single probability to an entire zone [16]. NFIP insurance rates are typically applied as a flat rate, such as the National Flood Insurance Program (NFIP) 500-year flood zone, or set by depth below a "base flood elevation" (the 1 in 100-year flood surface elevation). Flood probability interpolation can help to determine the probability of any single flood depth, or multiple flood depths. This allows for improved numerical integration over flood risk [28] for spatially resolved actuarial rate setting.

FEMA performs log-linear interpolation within the agency and publishes the output flood probability maps only for a few flood-prone communities. There are many floodprone communities where water surface elevation or depth data are available for a number 
of return periods but the percent annual chance data are not available. FLOPIT could be useful for these communities. Additionally, our study shows that in our chosen study area, log-linear was not the best interpolation option given that the log-spline method led to a reduced overall bias. While more refined investigations are needed, this study could be the start of a conversation in FEMA to replace log-linear with the log-spline method or at least make the interpolation method more flexible and generate probability maps using different interpolation methods.

Finally, FLOPIT is not only intended for use by FEMA data. There are agencies such (e.g., European's Joint Research Center) that generate flood inundation maps for a limited number of return periods and miss other return periods probably because of the considerable cost of generating these maps (e.g., computational and/or storage limitations). One could easily use FLOPIT and generate more flood maps using these available flood maps. In ungauged areas where flood inundation data are not available, FLOPIT could be used in combination with state-of-the-art models and tools that generate flood inundation maps [29-31].

\section{Conclusions}

FLOPIT is a tool that uses the relationship between flood surface elevation-probability and a digital elevation model to interpolate flood probabilities and produce flood inundation maps for new return periods. FLOPIT provides a fast and flexible resource for producing continuous flood probability maps to aid flood hazard communication and quantification. We demonstrate how flood zones can be a poor approximation to flood probability and can be downward biased in reported and communicated flooding probabilities. Flood probability interpolation tools can help address these issues by reducing the bias of spatially resolved flood probability maps. Refined flood probability maps can be useful to improve decisions, for example about where and how to build or whether to elevate a house, whether and how to change local zoning, and how to set fair flood insurance rates [9,32-35].

Supplementary Materials: The following are available online at https:/ /www.mdpi.com/2073-444 1/13/5/666/s1. Figure S1. Map of a roughly $3 \mathrm{~km}$ reach of the Susquehanna River and tributaries at Muncy, PA. Panel 1 shows the location Lycoming County and Muncy, PA. Panel 2 shows the FEMA floodplains, derived from FEMA flood surface elevation data for the $1 \%$ and $0.2 \%$ annual chance $(1$ in 100-year and 1 in 500-year) floods. Panel 3 shows the FLOPIT interpolated flood probabilities, from $10 \%$ to $0.2 \%$ annual chance (1 in 10-year to 1 in 500-year). Flood probabilities are almost always higher than the flood zone communicated probabilities. The Borough of Muncy is located in the center of the map, with large northern sections inside the flood zones; Figure S2. Map of a roughly $1.5 \mathrm{~km}$ reach of the Sims Bayou in Houston (TX). Panel (a) shows the location of Harris County and the Sims Bayou. Panel (b) shows the FEMA floodplains, derived from FEMA flood surface elevation data for the $1 \%$ and $0.2 \%$ annual chance (1 in 100-year and 1 in 500-year) floods. Panel (c) shows the FLOPIT interpolated flood probabilities, from $10 \%$ to $0.2 \%$ annual chance (1 in 10-year to 1 in 500 -year). Flood probabilities are always greater than or equal to the flood zone communicated probabilities; Figure S3. Box and whisker plot of the interpolated return period versus the FEMA flood zone return period for each map pixel of the Muncy map. Return periods in the $100(1 \%)$ year flood zone range from $10(10 \%)$ to $100(1 \%)$, and the average return period is roughly 20 years $(4 \%)$. Return periods in the 500-year zone range from $100(1 \%)$ to $500(0.2 \%)$, and the average is roughly $250(0.4 \%)$ years. Whiskers extend to maximum and minimum of data; Figure S4. Box and whisker plot of the interpolated return period versus the FEMA flood zone return period for each Sims Bayou in Houston (TX), map pixel. Flood probabilities in the 1 in 100 (1\% annual chance) flood zone range from 1 in 10 (10\% annual chance) to 1 in 100 (1\% annual chance), with an average flood probability of roughly 1 in 30 (3.3\% annual chance). Flood probabilities in the 1 in 500 ( $0.2 \%$ annual chance) zone range from 1 in $100(1 \%)$ to 1 in $500(0.2 \%)$, and the average is roughly 1 in 300 ( $0.33 \%$ annual chance). The solid green line illustrates a hypothetical perfect relationship. Whiskers extend to maximum and minimum of data; Figure S5. Box and whisker plot of the interpolated return period versus the FEMA flood zone return period for each map pixel of the Selinsgrove map. Return periods in the 100 $(1 \%)$ year flood zone range from $10(10 \%)$ to $100(1 \%)$, and the average return period is roughly 20 
years (4\%). Return periods in the 500-year zone range from $100(1 \%)$ to $500(0.2 \%)$, and the average is roughly $250(0.4 \%)$ years. Whiskers extend to maximum and minimum of data.

Author Contributions: K.K. contributed to the study's conceptual framework, the interpretation of the results, and writing the manuscript. K.J.R.-E.contributed to the study's conceptual framework, wrote the code in R, performed the analysis, and contributed to writing the manuscript. M.Z. revised the R code, wrote the Python code, and contributed to writing the manuscript. S.S. performed a code-review and edited the paper. All authors have read and agreed to the published version of the manuscript.

Funding: This study was co-supported by the US Department of Energy, Office of Science through the Program on Coupled Human and Earth Systems (PCHES) under DOE Cooperative Agreement No. DE-SC0016162 as well as the Penn State Center for Climate Risk Management. All errors and opinions (unless cited) are those of the authors and not of the funding entities.

Data Availability Statement: All results: model codes, analysis codes, data, and model outputs used for analysis are freely available from https://github.com/pches/FLOPIT/tree/revision_2020 and are distributed under the GNU general public license.

Acknowledgments: We thank Caitlin Spence, Courtney Cooper, Jared Oyler, Irene Schaperdoth, Rob Nicholas, Karen Fisher-Vanden, Luke Madaus, and Skip Wishbone for valuable inputs.

Conflicts of Interest: The authors declare no conflict of interest.

Disclaimer : The datasets, software tools, results, and any other resources associated with FLOPIT and this manuscript are intended for academic research and education (not for real-world decisionmaking) and provided as-is without warranty of any kind, express or implied. In no event shall the authors or copyright holders be liable for any claim, damages, or other liability in connection with the use of these resources.

\section{References}

1. Strömberg, D. Natural Disasters, Economic Development, and Humanitarian Aid. J. Econ. Perspect. 2007, 21, 199-222. [CrossRef]

2. (IFRC) International Federation of Red Cross and Red Crescent Societies. World Disasters Report 2016; IFRC: Paris, France, 2016. Available online: https://www.ifrc.org/Global/Documents/Secretariat/201610/WDR2016-FINAL_web.pdf (accessed on 3 July 2020).

3. Winsemius, H.C.; Aerts, J.C.J.H.; Van Beek, L.P.H.; Bierkens, M.F.P.; Bouwman, A.; Jongman, B.; Kwadijk, J.C.J.; Ligtvoet, W.; Lucas, P.L.; Van Vuuren, D.P.; et al. Global drivers of future river flood risk. Nat. Clim. Chang. 2016, 6, 381-385. [CrossRef]

4. Wing, O.E.J.; Bates, P.D.; Smith, A.M.; Sampson, C.C.; Johnson, K.A.; Fargione, J.; Morefield, P. Estimates of present and future flood risk in the conterminous United States. Environ. Res. Lett. 2018, 13, 034023. [CrossRef]

5. Hallegatte, S.; Green, C.; Nicholls, R.J.; Corfee-Morlot, J. Future flood losses in major coastal cities. Nat. Clim. Chang. 2013, 3, 802-806. Available online: http:/ / www.nature.com/nclimate/journal/v3/n9/full/nclimate1979.html\%5Cnhttp://www.nature. com/nclimate/journal/v3/n9/pdf/nclimate1979.pdf (accessed on 1 July 2020). [CrossRef]

6. Hirabayashi, Y.; Mahendran, R.; Koirala, S.; Konoshima, L.; Yamazaki, D.; Watanabe, S.; Kim, H.; Kanae, S. Global flood risk under climate change. Nat. Clim. Chang. 2013, 3, 816-821. [CrossRef]

7. Godschalk David, R. Urban Hazard Mitigation: Creating Resilient Cities. Nat. Hazards Rev. 2003, 4, 136-143. [CrossRef]

8. Kjellgren, S. Exploring local risk managers' use of flood hazard maps for risk communication purposes in Baden-Württemberg. Nat. Hazards Earth Syst. Sci. 2013, 13, 1857-1872. [CrossRef]

9. Zarekarizi, M.; Srikrishnan, V.; Keller, K. Neglecting uncertainties biases house-elevation decisions to manage riverine flood risks. Nat. Commun. 2020, 11, 1-11. [CrossRef]

10. (FEMA) The Federal Emergency Management Agency. Percent Annual Chance Data; FEMA: Washington, DC, USA, 2015. Available online: https:/ / www.fema.gov / media-library-data/1522157767608-ed99f04df13b5b7239922b3e77b7f8ea/FactSheetPercentAnnualChanceData.pdf (accessed on 3 July 2020).

11. Ludy, J.; Kondolf, G.M. Flood risk perception in lands “protected" by 100-year levees. Nat. Hazards 2012, 61, 829-842. [CrossRef]

12. Smith, D.I. Floodplain management: Problems, issues and opportunities. Floods 2000, 1, 254-267.

13. Alfieri, L.; Salamon, P.; Bianchi, A.; Neal, J.C.; Bates, P.D.; Feyen, L. Advances in pan-European flood hazard mapping. Hydrol. Process. 2014, 28, 4067-4077. [CrossRef]

14. Jafarzadegan, K.; Merwade, V.; Saksena, S. A geomorphic approach to 100-year floodplain mapping for the Conterminous United States. J. Hydrol. 2018, 561, 43-58. [CrossRef]

15. Woznicki, S.A.; Baynes, J.; Panlasigui, S.; Mehaffey, M.; Neale, A. Development of a spatially complete floodplain map of the conterminous United States using random forest. Sci. Total. Environ. 2019, 647, 942-953. [CrossRef] 
16. (FEMA) The Federal Emergency Management Agency. Guidance for Flood Risk Analysis and Mapping; FEMA: Washington, DC, USA, 2018. Available online: https://www.fema.gov/media-library-data/1523562952942-4c54fdae20779bb004857f1915236e6c/ Flood_Depth_and_Analysis_Grids_Guidance_Feb_2018.pdf (accessed on 3 July 1998).

17. Luke, A.; Sanders, B.F.; Goodrich, K.A.; Feldman, D.L.; Boudreau, D.; Eguiarte, A.; Serrano, K.; Reyes, A.; Schubert, J.E.; AghaKouchak, A.; et al. Going beyond the flood insurance rate map: Insights from flood hazard map co-production. Nat. Hazards Earth Syst. Sci. 2018, 18, 1097-1120. [CrossRef]

18. Soden, R.; Sprain, L.; Palen, L. Thin Grey Lines. In Proceedings of the 2017 CHI Conference on Human Factors in Computing Systems, Denver, CO, USA, 6-11 May 2017; pp. 2042-2053.

19. McClelland, G.H.; Schulze, W.D.; Coursey, D.L. Insurance for low-probability hazards: A bimodal response to unlikely events. J. Risk Uncertain. 1993, 7, 95-116. [CrossRef]

20. Oberholzer-Gee, F. Learning to Bear the Unbearable: Towards an Explanation of Risk Ignorance; Mimeo, Wharton School, University of Pennsylvania: Philadelphia, PA, USA, 1998.

21. (FEMA) The Federal Emergency Management Agency. Guidance for Flood Risk Analysis and Mapping; FEMA: Washington, DC, USA, 2020. Available online: https:/ / www.fema.gov/sites/default/files/documents/fema_flood-depth-and-analysis-guidance.pdf (accessed on 3 July 2020).

22. Yamazaki, D.; Ikeshima, D.; Sosa, J.; Bates, P.D.; Allen, G.H.; Pavelsky, T.M. MERIT Hydro: A High-Resolution Global Hydrography Map Based on Latest Topography Dataset. Water Resour. Res. 2019, 55, 5053-5073. [CrossRef]

23. Fritsch, F.N.; Carlson, R.E. Monotone Piecewise Cubic Interpolation. SIAM J. Numer. Anal. 1980, 17, 238-246. [CrossRef]

24. Gesch, D.; Oimoen, M.; Greenlee, S.; Nelson, C.; Steuck, M.; Tyler, D. The National Elevation Dataset. Photogramm. Eng. Remote. Sens. 2002, 68, 5-32.

25. (PAMAP, 2020) Pennsylvania Spatial Data Access. PAMAP Program. Available online: https://www.dcnr.pa.gov/Geology/ PAMAP/Pages/default.aspx (accessed on 3 July 2020).

26. Taheri, S.; Briggs, I.; Burtscher, M.; Gopalakrishnan, G. DiffTrace: Efficient Whole-Program Trace Analysis and Diffing for Debugging. In Proceedings of the 2019 IEEE International Conference on Cluster Computing (CLUSTER), Albuquerque, NM, USA, 23-26 September 2019; pp. 1-12.

27. Taheri, S.; Devale, S.; Gopalakrishnan, G.; Burtscher, M. ParLoT: Efficient Whole-Program Call Tracing for HPC Applications. In Computer Vision; Springer International Publishing: Dallas, TX, USA, 2019; pp. 162-184.

28. Kron, W. Flood Risk $=$ Hazard $\times \cdot$ Values $\times \cdot$ Vulnerability. Water Int. 2005, 30, 58-68. [CrossRef]

29. Schumann, G.; Hostache, R.; Puech, C.; Hoffmann, L.; Matgen, P.; Pappenberger, F.; Pfister, L. High-Resolution 3-D Flood Information From Radar Imagery for Flood Hazard Management. IEEE Trans. Geosci. Remote. Sens. 2007, 45, 1715-1725. [CrossRef]

30. Cohen, S.; Brakenridge, G.R.; Kettner, A.; Bates, B.; Nelson, J.; McDonald, R.; Huang, Y.-F.; Munasinghe, D.; Zhang, J. Estimating Floodwater Depths from Flood Inundation Maps and Topography. JAWRA J. Am. Water Resour. Assoc. 2018, 54, 847-858. [CrossRef]

31. Scorzini, A.R.; Radice, A.; Molinari, D. A New Tool to Estimate Inundation Depths by Spatial Interpolation (RAPIDE): Design, Application and Impact on Quantitative Assessment of Flood Damages. Water 2018, 10, 1805. [CrossRef]

32. Frazier, T.; Boyden, E.E.; Wood, E. Socioeconomic implications of national flood insurance policy reform and flood insurance rate map revisions. Nat. Hazards 2020, 1-18. [CrossRef]

33. Karamouz, M.; Fereshtehpour, M.; Ahmadvand, F.; Zahmatkesh, Z. Coastal Flood Damage Estimator: An Alternative to FEMA's HAZUS Platform. J. Irrig. Drain. Eng. 2016, 142, 04016016. [CrossRef]

34. Kousky, C.; Kunreuther, H.; LaCour-Little, M.; Wachter, S. Flood Risk and the U.S. Housing Market. J. Hous. Res. 2020, 29 , S3-S24. [CrossRef]

35. Thaler, T.; Hartmann, T. Justice and flood risk management: Reflecting on different approaches to distribute and allocate flood risk management in Europe. Nat. Hazards 2016, 83, 129-147. [CrossRef] 